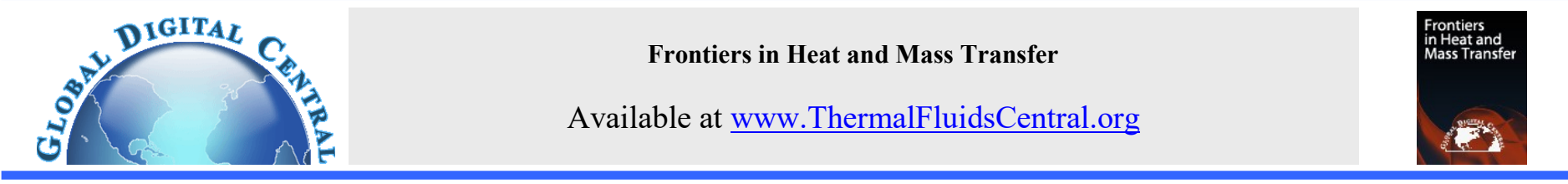

\title{
ON THE MECHANISM OF BUBBLE INDUCED FORCED CONVECTIVE HEAT TRANSFER ENHANCEMENT
}

\author{
Clement Roy ${ }^{\mathrm{a},}{ }^{*}$, Prasanna Venuvanalingam ${ }^{\mathrm{b}}$, James F. Klausner ${ }^{\mathrm{a}}$, Renwei Mei ${ }^{\mathrm{c}}$ \\ a Michigan State University, East Lansing, MI, 48824, USA \\ ${ }^{b}$ Siemens Product Lifecycle Management Software, Orlando, FL, 32835, USA \\ ${ }^{c}$ University of Florida, Gainesville, FL, 32611, USA
}

\begin{abstract}
This article presents both an experimental and numerical study of both stationary and sliding bubbles in a horizontal duct with forced convection heat transfer. An experimental facility was fabricated using a fully transparent, electrically-heated test section in which the bubble dynamics and the thermal field on the heated wall can be acquired using high-speed cameras and Thermochromic Liquid Crystals (TLC). Experiments were conducted using the working fluid HFE 7000 for two different turbulent Reynolds numbers. The experimental temperature field in the span-wise direction is first compared to the numerically calculated temperature field of a bubble sliding near a wall and second to the temperature field calculated for a stationary bubble under the same flow and thermal conditions. In both cases the thermal field influence of the microlayer thickness, bubble shape, and the presence of multiple bubbles is investigated. An important outcome is that, unlike the sliding bubble case, the temperature field calculated in the stationary case is in agreement with the experimental results. The temperature field does not show any significant sensitivity to the micro-layer thickness or the bubble shape. It is concluded that the mechanism of heat transfer enhancement due to growing bubbles in forced convection is due to the flow perturbation induced by the bubble at the growth site or injection site rather than the thermal boundary layer disruption of the sliding bubbles. This is the reason flow boiling superposition correlations have success in predicting heat transfer without considering the bubble sliding process.
\end{abstract}

Keywords: Turbulent, Sliding, Boiling

\section{INTRODUCTION}

The study of bubbly flows in forced convective heat transfer is a widely debated topic due to its inherent complexity. Specifically, the role of sliding bubbles in enhancing bulk turbulent convection in flow boiling applications is poorly understood. Understanding how bulk turbulent convection is enhanced by sliding bubbles is important in formulating predictive models for important industrial applications such as chemical processing, nuclear power, heating, and cooling among others.

Based on the assumption that the global heat transfer coefficient is the sum of the heat transfer due to bulk turbulent convection and that due to nucleate boiling, Chen (1966) developed a superposition model to determine the heat transfer coefficient for saturated flow boiling. Basu et al. (2005) and Yeoh et al. (2008) improved on the Chen model by taking into account the number of nucleation sites, the growing time, the sliding time, and the transient conduction. They attributed as much as $50 \%$ of the heat transfer to sliding bubbles. Experimentally, Kenning and Kao (1972) noticed that bubble injection in an upward flow leads to a 50\% increase in the heat transfer coefficient depending on the Reynolds number. They suspected the secondary flow generated by the bubble to be responsible for that increase. This result was confirmed by Thorncroft et al. (1998) for upward flow with bubble injection. To explain this heat transfer enhancement, Kitagawa et al. (2008) observed the velocity field and the heat transfer enhancement around a bubble sliding along a heated wall in natural convection. They concluded that heat transfer enhancement is directly affected by the flow modification due to bubble sliding. Donnelly et al. (2015) and O'Reilly Meehan et al. (2017) used an IR camera to study sliding air bubbles through a quiescent pool of water. Their results demonstrate that the local heat transfer coefficient is affected by both the bubble Reynolds number and shape. Due to the complexity and unsteady phenomena involved, such as convection between the bubble and the bulk turbulent flow or fluid-bubble interaction during bubble growth and sliding, numerical studies are difficult. Son (2001) numerically studied bubble sliding on a vertical heater in a natural convection configuration. It was observed that enhancement in heat transfer increased with a rise in bubble sliding velocity and superheating at the wall. Kim and Lee (2017) used the volume of fluid method to study the heat transfer due to bubble impinging a heated wall. They observed heat transfer enhancement as the bubble impinges the surface. The results show that the heat transfer coefficient significantly increases in the region where the bubble adheres to the wall and passes over the hydrophobic portion of the surface as opposed to bubbles bouncing off the surface.

The focus of this investigation is to understand the mechanism of heat transfer enhancement due to bubble sliding in forced convective turbulent flow, which has different heat transfer implications than sliding bubbles in quiescent flow. The approach is to develop an experimental facility where the heater surface temperature field can be measured with injected sliding bubbles. A parallel numerical simulation is developed to gain better insight into how bubbles enhance the bulk turbulent convective heat transfer. It will be demonstrated that the dominant enhancement mechanism is due to the wake created behind the bubble when the bubble Reynolds number is the highest (at the bubble generation site), just prior to bubble detachment. 


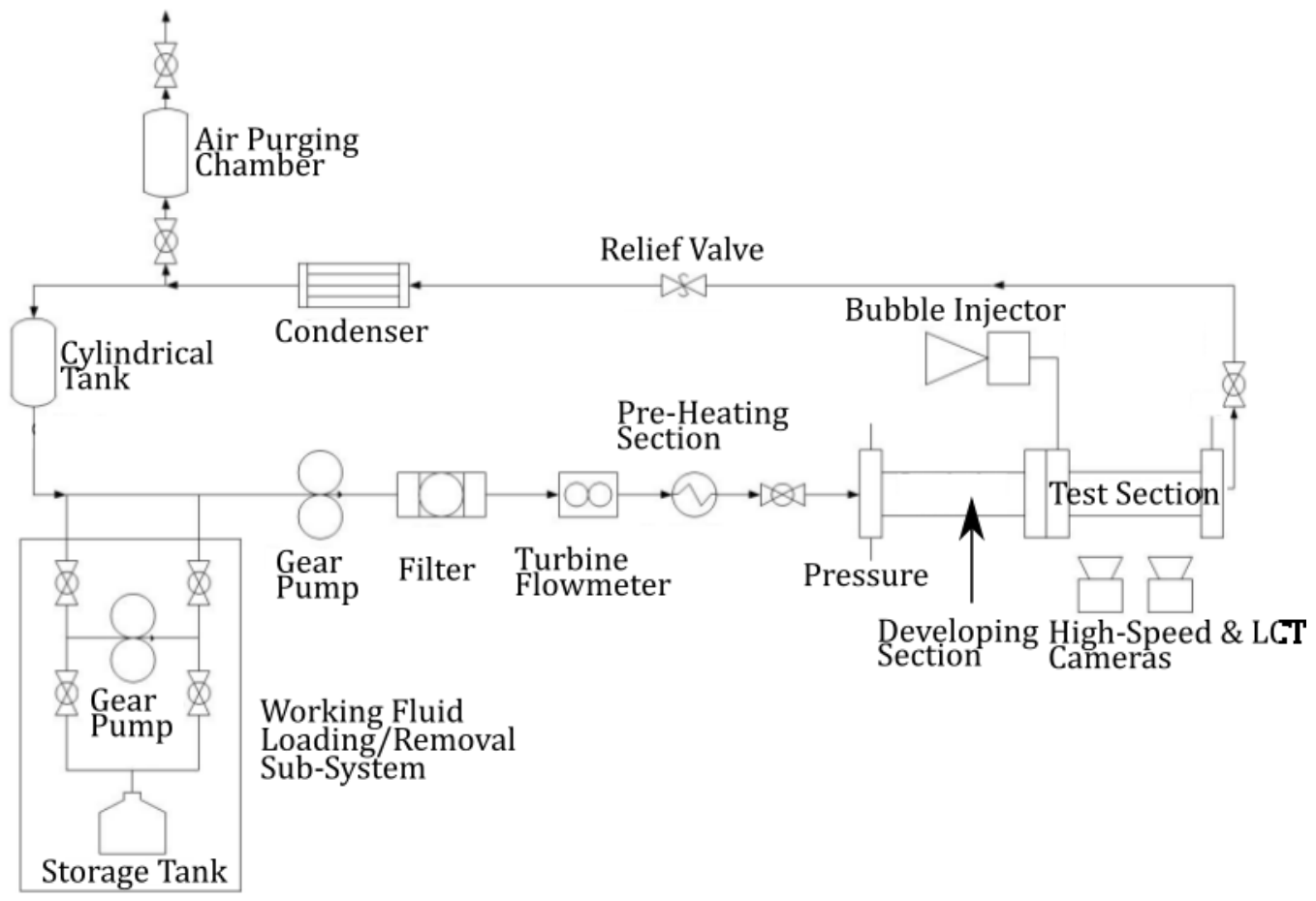

Fig. 1 Schematic flow diagram of the experimental heat transfer facility.

\section{EXPERIMENTAL FACILITY}

\subsection{Flow Boiling Facility Overview}

For this study, a new forced convective heat transfer facility has been designed and fabricated in order to satisfy the experimental requirements. The facility is capable of making 2D surface temperature measurements and capturing bubble size and speed using Thermochromic Liquid Crystals (TLC) on the heated wall with a visual flow-field access from three other walls. A schematic flow diagram of the facility is shown in Fig. 1. A variable DC gear pump is used to put the fluid in motion. The fluid used during these experiments is HFE 7000 due to its low saturation temperature $\left(34^{\circ} \mathrm{C}\right.$ at atmospheric pressure) and its chemical compatibility with the TLC coating. The fluid properties at atmospheric pressure are summarized in Table 1 . The fluid passes through a filter to remove impurities that could alter fluid properties and deteriorate the TLC coating. The flow rate is measured using a turbine flow meter and enters the pre-heating section, followed by the developing section and the main test section. A heat flux is applied from the top wall of the test section using a $50 \mu \mathrm{m}$ thick stainless-steel foil heater. At the entrance of the main test section, a needle injects bubbles initiating the bubble sliding process. The temperature on the heating foil is measured using Liquid Crystal Thermography (LCT) and bubble dynamics are acquired with two high-speed cameras. An in-house, post-processing algorithm is used to analyse bubble dynamics and trajectories. Finally, the fluid successively passes through the condenser and returns to a cylindrical holding tank. Air is captured in a purge chamber and removed from the system.

\subsection{Developing and Main Test Section}

The developing section is used to ensure fully developed turbulent flow at the main test section entrance. According to Sparrow et al. (1966), it requires approximately 40 hydraulic diameters for the flow to be fully turbulent and thermally developed in symmetrical ducts. The developing section is 0.57 meter long and made of polypropylene for its rigidity and its ability to endure elevated temperatures. This material also provides a satisfactory thermal insulation $(0.1<\mathrm{k}<0.22)$ and is chemically inert. The principal issue with polypropylene is its difficulty to bond and obtain a leak-proof assembly. Epoxy B-481TH from Reltek is used for its chemical compatibility with the working fluid (HFE7000) and ability to adhere to polypropylene. The main test section was the most challenging component to construct for this experiment. The limited lifetime of TLCs require that this section must be easy to disassemble and reassemble. However it is also necessary to limit the number of parts in order to minimize the amount of joints that could potentially fail during the experiment. Ultimately, to allow visual access to the TLCs and bubble trajectories, transparency is required for all four sides. The final design shown in Fig. 2 is a cross-sectional view of the assembly, and Fig. 3 shows a detailed view of the coating on the heater surface.

Table 1 Thermophysical properties of HFE 7000 at $25^{\circ} \mathrm{C}$.

\begin{tabular}{lrr}
\hline Property & Values & \multicolumn{1}{c}{ Units } \\
\hline Density & 1400 & $\mathrm{~kg} \cdot \mathrm{m}^{-3}$ \\
Specific Heat & 1300 & $\mathrm{~J} \cdot \mathrm{kg}^{-1} \cdot \mathrm{K}^{-1}$ \\
Surface Tension & 0.0124 & $\mathrm{~N} \cdot \mathrm{m}^{-1}$ \\
Kinematic Viscosity & $3.2 \times 10^{-7}$ & $\mathrm{~m}^{2} \cdot \mathrm{s}^{-1}$ \\
Thermal Conductivity & 0.075 & $\mathrm{~W} \cdot \mathrm{m}^{-1} \cdot \mathrm{K}^{-1}$ \\
Latent Heat & 142 & $\mathrm{~kJ} \cdot \mathrm{kg}^{-1}$ \\
\hline
\end{tabular}

The material used for the test section channel is polycarbonate, mainly due to its transparency, allowing visual access to the flow field. The bottom, left, and right walls of the duct comprise a single component, which limits the number of joints in addition to increasing the duct stiffness. To maintain high pressure seals and easy assembly/disassembly, the sealing gaskets are compressed using mechanical fasteners along the full length of the test section. Threaded inserts were placed along each side of the test section's top part, and pressure is applied on the gaskets by bolting directly into the part. The bubble injection system consists of a syringe pump connected to a hypodermic needle that is located in the test section as shown in Fig. 2. 
Table 2 Measurement uncertainties.

\begin{tabular}{lcrrr}
\hline Measurement & Error Magnitude & \multicolumn{1}{c}{ Range } & \multicolumn{1}{c}{ Units } & Error Uncertainty (\%) \\
\hline Temperature & $2.00 \times 10^{-1}$ & $38.21-38.5$ & ${ }^{\circ} \mathrm{C}$ & 0.52 \\
Temperature (LCT) & $4.90 \times 10^{-1}$ & $38.5-41.5$ & ${ }^{\circ} \mathrm{C}$ & 1.27 \\
Flow Rate & $1.30 \times 10^{-1}$ & $0.6-0.84$ & $L P M$ & 15.47 \\
Pressure & $3.76 \times 10^{2}$ & $(-)$ & $P a$ & $(-)$ \\
Heat Flux & $4.63 \times 10^{1}$ & $1714-1740$ & $W . m^{-2}$ & 2.7 \\
Bubble Position & $8.80 \times 10^{-5}$ & $0-0.006$ & $m$ & 1.5 \\
Bubble Velocity & $8.80 \times 10^{-5}$ & $0-0.18$ & $m . s^{-1}$ & 0.05 \\
\hline
\end{tabular}

The inner diameter and outer diameter of the needle are $255 \mu \mathrm{m}$ and 355 $\mu \mathrm{m}$ respectively. To avoid any heat transfer between the bulk flow and the bubbles, the injected air is preheated to the bulk flow temperature.

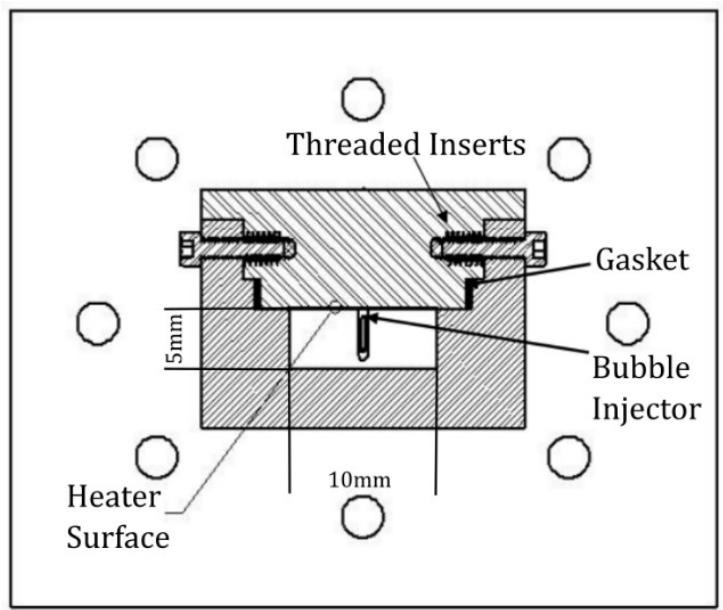

Fig. 2 Cross-sectional view of the main test section.

\subsection{Measurements}

Apart from acquiring the heater surface temperature field and bubble dynamic behavior, it is necessary to measure the bulk flow characteristics such as flow rate and both temperature and pressure at the test section inlet and outlet. Temperature measurements are done using E and T type thermocouples calibrated using a NIST traceable digital thermistor with a resolution of $0.001^{\circ} \mathrm{C}$ and an accuracy of $\pm 0.05^{\circ} \mathrm{C}$. The uncertainty estimation on temperature is $\pm 0.2^{\circ} \mathrm{C}$, using the procedure developed by Kline and McClintock (1953). Pressure measurements are made using a differential pressure transducer (one side of the transducer is open to atmosphere) that is calibrated against a mercury manometer from 0 to $250 \mathrm{kPa}$. The uncertainty is $\pm 376 \mathrm{~Pa}$. Table 2 summarizes all measured uncertainties. Instrument signals are acquired using a National Instruments digital data acquisition system, model USB-6225. It has 80 channels with 16-bit resolution. The sampling rate used in this study is 1 $\mathrm{kHz}$. A LabVIEW program is used to acquire, process, and store the data in an Excel sheet for further analysis.

\section{LIQUID CRYSTAL THERMOGRAPHY}

Liquid Crystal Thermography (LCT) is a well-known measuring technique in heat transfer to measure 2D temperature fields. This method is based on the use of Thermochromic Liquid Crystals that change color as a function of the temperature. They usually come in two forms: encapsulated and un-encapsulated crystals. In this study the encapsulated form is used with a nominal bandwidth of $20^{\circ} \mathrm{C}$ and temperature range between $30^{\circ} \mathrm{C}$ and $50^{\circ} \mathrm{C}$.

\subsection{TLC Application to Heater Surface}

Wagner and Stephan (2007) described the different state of TLCs as a function of the temperature. In their active range, they are available in a slurry state. To obtain a thin and homogeneous thickness, TLCs are typically sprayed using an airbrush. The same technique is employed after first applying a black undercoating necessary for contrast to observe the color change as shown in Fig. 3. A high temperature optically clear double-sided tape supplied by $3 \mathrm{M}$ (9483) is used to adhere the heater to the polypropylene test section. It is then assumed that the temperature measured by the TLCs is the temperature at the solid liquid interface, which can be justified since the Biot number associated with the thin foil heater is on the order of 0.1 . Therefore, the temperature change across the heater is negligibly small. As shown on Fig. 3a, the TLC coating does not cover the heater edges to ensure that there is direct adhesion of the tape on the metallic portion of the heater.

(a)

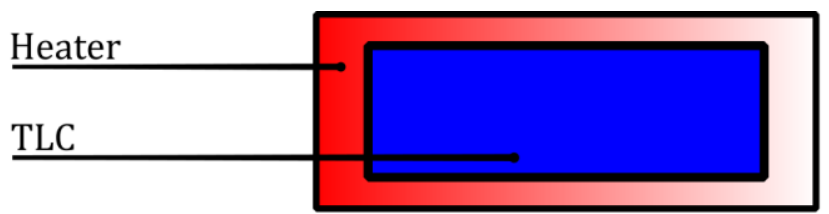

(b)

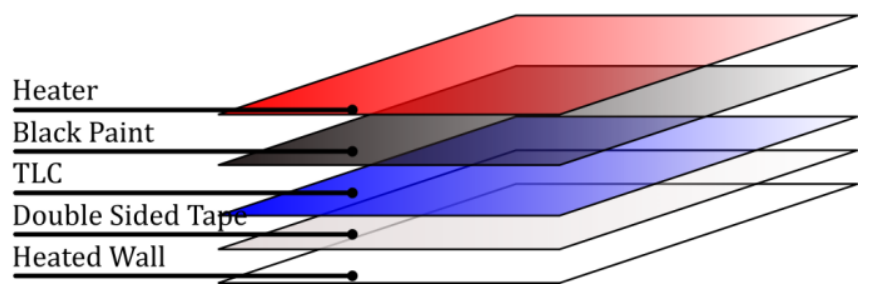

Fig. 3 Heating surface coating layers. (a) Bottom view, (b) Layering

\subsection{Calibration \& Response Time}

The image acquisition for LCT is made using a Phantom Miro Ex2 camera. This camera possess a $22 \mu \mathrm{m}$ physical pixel size and a resolution of $640 \times 480$ pixels. The camera is perpendicularly positioned to the TLC coating. An important measurement issue discussed by Sabatino et al. (2000) is the importance of the lighting axis. They showed that the incident light can produce an unwanted glare and distort the results. To overcome this issue, an off-axis lighting arrangement combined with a polarizer and a full spectrum fluorescent light source from Alzo Digital is used. The lighting source was chosen because it maintains a constant intensity without flickering, and the thermal radiation is minimal. Calibration is a widely debated topic when using TLCs. The pixel wise calibration proposed by Sabatino et al. (2000) is employed because using this method, each pixel has its own calibration curve, thus eliminating the effects of any variability parameters such as lighting non uniformity, coating thickness and viewing angle. Like Muwanga and Hassan (2006) and Wagner and Stephan (2007) most researchers convert RGB values into a hue and then the calibration curve gives the temperature as a function of the hue. To reduce the uncertainty, the temperature is directly 
extracted as a function of the RGB values using the following polynomial equation:

$$
T(R, G, B)=C_{1}+C_{2} R+C_{3} G+C_{4} G^{2}+C_{5} \frac{B}{R}
$$

This function was chosen through optimization to reduce the measurement uncertainty. Using Eq. (1) the temperature uncertainty is $\pm 0.49^{\circ} \mathrm{C}$. The study of sliding bubbles requires a short response time for the measurement system. Ireland and Jones (1987) studied the response of un-encapsulated TLCs and reported a response time below $10 \mathrm{~ms}$. Concerning the frequency response of TLCs, Wagner and Stephan (2007) reported a maximum of $70 \mathrm{~Hz}$. This is due to the difficulty in controlling the coating thickness. Therefore, in this study, measurements made using TLCs are averaged over a long time and considered quasisteady estimates.

\section{DIGITAL IMAGE PROCESSING}

In addition to measuring the temperature field, the measurement setup has been designed to record bubble size, position, and velocity. A NAC HiDCAM high-speed camera is used for recording at 1000 FPS with a resolution of 1280 x 256 pixels coupled with a $50 \mathrm{~mm}$ focal length Nikon macro lens. The known diameter $(355 \mu \mathrm{m})$ of the injection needle is used to calibrate a pixel into a physical dimension. For this setup, a pixel corresponds to $44 \mu \mathrm{m}$. Lindken and Merzkirch (2001) used a thresholding technique to identify the contour of a bubble. The same technique is employed here and every image is compared with the background image to obtain a binary image. Figure 4 illustrates the four steps of the image processing technique. Figure $4 \mathrm{a}$ is the original image captured. This image is then compared to the background image; any pixel above the sum of the background intensity plus a defined threshold is termed lighter. The result is shown in Fig. 4b. A similar result for the darker pixels is shown in Fig. 4c. Finally the two images are summed and the result is Fig. 4d. The next operation (the contour fill) consists of detecting and filling the pixels that could not be differentiated from the background but are part of the bubble. This is achieved by turning to white all the pixels that reside between the farthest white pixels in a given column. The result is shown in Fig. 5b with a binary image of the bubble. Bubble velocities, stream-wise separation, and lateral separation are then estimated from the change in the center coordinates using Eqs. (2) and (3) in successive frames with a known frame rate.

$$
\begin{aligned}
& \left\{\begin{array}{l}
x_{c}=\frac{\sum_{i} \sum_{j} x I(x, y)}{\sum_{i} \sum_{j} I(x, y)} \\
y_{c}=\frac{\sum_{i} \sum_{j} y I(x, y)}{\sum_{i} \sum_{j} I(x, y)}
\end{array}\right. \\
& d=\sqrt{\frac{4 \sum_{i} \sum_{j} I(x, y)}{\pi}}
\end{aligned}
$$

These values are averaged over thousands of bubbles, and uncertainties are listed in Table 2.

\section{EXPERIMENTAL PROCEDURE}

The working fluid is circulated through the experimental facility, and heat is input to the pre-heating section until the fluid reaches the active range of TLCs. The heat input is then fixed to reach steady-state temperature. While the fluid is pre-heated, the bubble injection system is charged and set to discharge air bubbles at a constant flow rate. When steady-state is reached the main heater section is then switched on and the heat flux is adjusted to maintain the fluid temperature within the

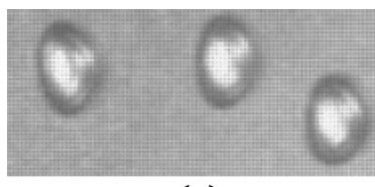

(a)

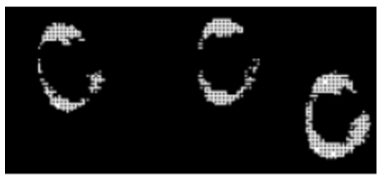

(c)

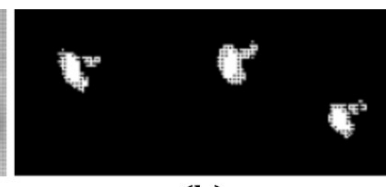

(b)

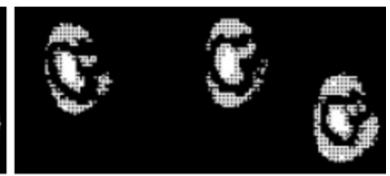

(d)
Fig. 4 (a) Original image, (b) Pixels lighter than background, (c) Pixels darker than background, and (d) Sum of lighter and darker pixels.

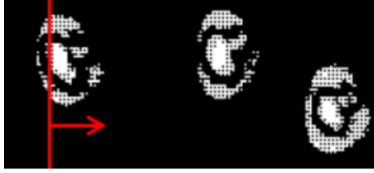

(a)

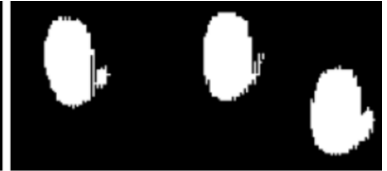

(b)
Fig. 5 Contour filling process. (a) Sum of lighter and darker pixels, (b) Final binary image.

TLC active range but also to prevent any incipient boiling. This is accomplished by observing the color change pattern of the TLCs and adjusting the heat flux accordingly. Since the response time of the system is close to one hundred seconds, recording and data acquisition are initialized two minutes after the heat flux is set. The recording duration of the high-speed RGB camera capturing the TLC color change is 15 minutes. Due to a recording length constraint, the recording procedure for the second high-speed camera, which acquires the bubble dynamics, is different. Only 100 frames are recorded at the beginning of each minute. At the end, both the recordings are converted into an "avi" format for processing. The heat flux is then slowly lowered to avoid the formation of bubbles that could degrade the double-sided tape adhesive. It is emphasized here that the main heating section is operated in an inverted position (as shown in Fig. 2) where the heated wall is downward facing and in contact with the upper portion of the flow field. Thus, gravity acts to push the injected bubbles up against the heated surface, and the bubbles slide along the upper heated surface.

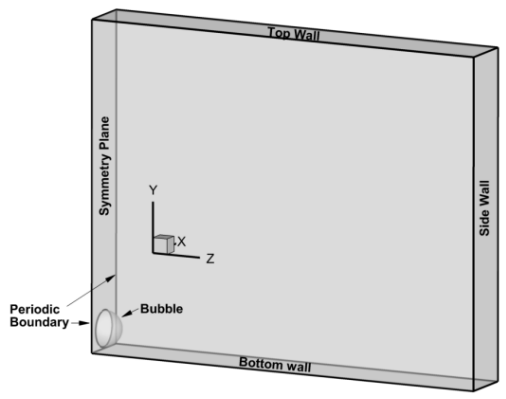

Fig. 6 Computational domain geometry for bubble sliding case.

\section{NUMERICAL ANALYSIS}

\subsection{Numerical Assumptions}

According to the literature, the main parameters governing the heat transfer coefficient enhancement are the bubble shape, bubble relative velocity, and the micro-layer thickness. Unfortunately, these parameters 


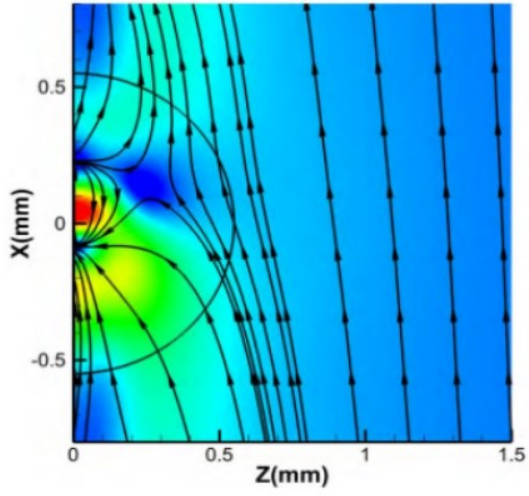

(a)

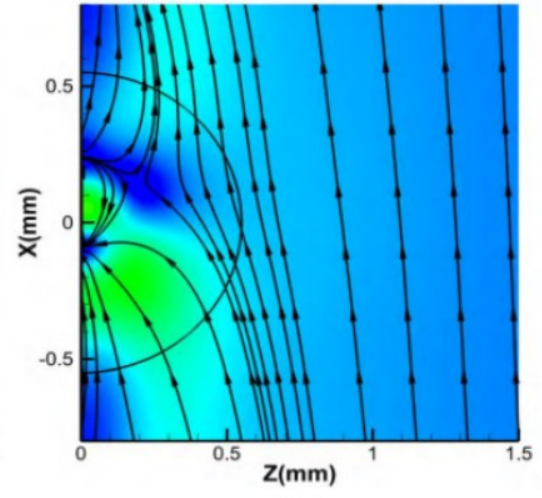

(b)

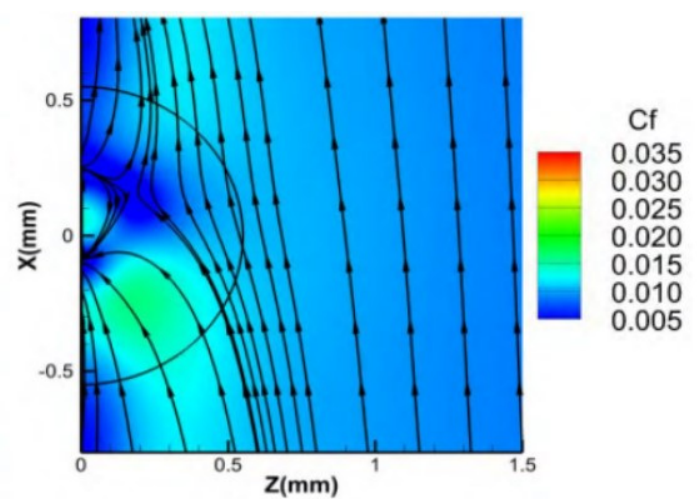

(c)

Fig. 7 Contour plot of skin friction coefficient on the heater surface combined with streamlines. (a) $50 \mu \mathrm{m}$, (b) $75 \mu \mathrm{m}$, (c) $100 \mu \mathrm{m}$

are very difficult to control in an experiment and therefore must be studied with a computational model. For this work, the commercial code STAR-CCM+ is used. It employs finite volume discretization to solve the governing equations and uses a segregated flow model using a pressure-velocity coupling algorithm to solve the Navier-Stokes equations. A k- $\varepsilon$ turbulence model with an elliptic relaxation proposed by Durbin (1991) is used to model the anisotropic turbulence near the wall. It is emphasized here that in every computational case, gravity is deactivated. Therefore the bottom wall in the simulation corresponds to the downward facing surface in the experiment. In order to validate the code, it was tested on three different test cases that are relevant for the physics that this study is proposing to model: 1) potential flow around a sphere near a wall, 2) drag force on a spherical bubble in an unbounded domain, and 3) turbulent channel flow with asymmetrical heating. Each test case was compared with an exact solution or a validated model. The solution from the first test case was compared with the exact solution proposed by Weiss (1944). The results for the second test case were compared with the correlation proposed by Mei et al. (1994). Finally, the results for the last test case were validated against the widely accepted correlation proposed by Dean (1978).

\subsection{Periodic Bubble Sliding}

In order to study the bubble sliding heat transfer enhancement mechanism, the experimental methodology proposed by Kenning and Kao (1972), Thorncroft et al. (1998), and Ozer et al. (2011) is used here. Gas bubbles are injected onto a downward facing heater using a hypodermic needle. Therefore, the buoyancy forces pushes the bubble against the heater and avoids having them lift-off from the heater surface. For the purpose of the simulation, at the point of bubble detachment (the bubble leaving the injection site), the bubble velocity is initially nil, and quickly accelerates to a steady state. It is then assumed that downstream of the injection site, the bubble motion is steady and bubble spacing and velocities are identical for all sliding bubbles. Therefore, the computation can be done for a single bubble assuming a periodic boundary condition in the stream wise direction.

Domain Geometry, Mesh \& Boundary Conditions The computational domain is shown in Fig. 6. Its origin is located at the center of the sphere and the dimensions are given in millimeters below where $\varepsilon$ is the micro-layer thickness and " $\mathrm{d}$ " is the diameter of the sphere.

$$
\left\{\begin{array}{c}
-0.8<x<0.8 \\
\left(\frac{d}{2}+\varepsilon\right)<y<10-\left(\frac{d}{2}+\varepsilon\right) \\
0<z<12.5
\end{array}\right.
$$

The thermal and hydrodynamic boundary conditions and governing flow parameters used in the sliding bubble case are summarized in Table 3 and Table 4. The high fluid Prandtl number made the mesh creation a challenging task. The final mesh uses flow aligned hexahedral cells. At the near wall region the mesh size is $25 \mu \mathrm{m}$. The bubble growth requires that the top wall region possess $200 \mu \mathrm{m}$ cells. In the bubble region the mesh uses $6.75 \mu \mathrm{m}$ prismatic cells. It is ensured that the thinnest region between the bubble and the wall possess at least 16 cells. The cell size and number at the thinnest region were proven to give sufficient accuracy when comparing the pressure distribution at the wall with the exact solution from Weiss (1944).

Table 3 Boundary conditions specified for periodic bubble sliding analysis.

\begin{tabular}{lll}
\hline Boundary & Hydrodynamic & Thermal \\
\hline Inlet & Periodic Boundary & Periodic Boundary \\
Outlet & Periodic Boundary & Periodic Boundary \\
Bubble & No Shear & Adiabatic \\
Bottom Wall & No Slip & Constant Heat Flux \\
Side Wall & No Slip & Adiabatic \\
Symmetry Plane & Symmetry Plane & Symmetry Plane \\
Top Wall & No Slip & Adiabatic \\
\hline
\end{tabular}

Micro-Layer Thickness Influence Measuring the micro-layer thickness is a complicated task. Addlesee and Cornwell (1997), Addlesee and Kew (2002), and Li et al. (2006) reported that in forced convection flow boiling, the micro-layer thickness might vary between $50 \mu \mathrm{m}$ and $100 \mu \mathrm{m}$. Three different micro-layer thicknesses are studied in this work: $50 \mu \mathrm{m}, 75 \mu \mathrm{m}$, and $100 \mu \mathrm{m}$. The bubble Reynolds number calculated in Table 4 is based on the relative velocity at the center of the bubble. For each micro-layer thickness, the computed skin friction coefficient follows the standard definition:

$$
C_{f}=\frac{\tau_{w}}{\frac{1}{2} \rho U^{2}}
$$

Figure 7 illustrates the flow pattern near the wall with skin friction coefficient contours for three different micro-layer thicknesses. The skin friction coefficient calculated in the bubble far field agrees with Dean (1978) for turbulent duct flows. The peak skin friction coefficient increases when the micro-layer thickness diminishes, which could be expected by the increasing neck effect. The streamlines show a recirculation pattern below the bubble. This is due to the difference between the bubble speed, which is almost the bulk flow speed, and the near zero velocity close to the wall. The bubble pushes the liquid ahead, which gets drawn into the wake behind. This behavior is consistent for all three cases. In order to have a meaningful comparison between the 
experimental and numerical data, the computed temperature distributions in Fig. 8, Fig. 9, and Fig. 11 are averaged in the stream-wise direction after the bubble has reached steady state. Figure 8 shows the temperature distribution in the span-wise direction for the flow condition summarized in Table 4. The temperature profiles in Fig. 8 show the independence of the heat transfer enhancement to the micro-layer thickness. The enhanced cooling as reflected in the large experimental temperature drop is far more significant than that computed for the sliding bubbles. This observation seriously raises doubt that the thermal boundary layer disruption caused by sliding bubbles is solely responsible for the large cooling effect. At both span extremities, the cooling effect is diminished and the measured temperatures match those computed. It is emphasized here that no evaporative heat transfer is taking place even if the measured wall temperatures are above saturation temperature because the subcooling is strong enough to suppress boiling.

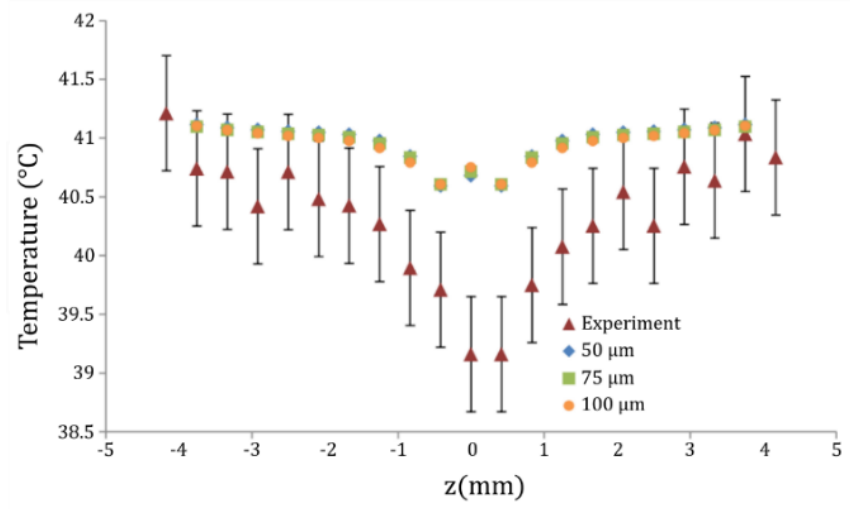

Fig. 8 Temperature distribution obtained from the experiment and the simulation for different micro-layer thicknesses.

Bubble Shape Influence Bubble shape is another key parameter that influences the flow field. However, due to the number of forces acting on a bubble imbedded in shear flow as described by Thorncroft et al. (2001), obtaining an accurate model on dynamic bubble shape is a complex problem. Therefore, only three different shapes are considered here for simplicity: full sphere, $50 \%$ truncated sphere, and $25 \%$ truncated sphere. In all cases, the micro-layer thickness is kept constant at $50 \mu \mathrm{m}$. Figure 9 shows a slight increase of the peak temperature drop with an increase in bubble truncation. It is attributed to an increase in the thermal boundary layer disruption caused by the rise of the base area. However, neither variations in micro-layer thickness or bubble shape can explain the large peak wall temperature drop observed in the experiments. After examining many different experimental measurements compared with computations, it is concluded that the large cooling effect is not likely due to the thermal boundary layer disruption occurring during the bubble sliding process as opposed to being the main heat transfer enhancement mechanism typically claimed in the literature.

Table 4 Governing flow parameters for periodic bubble sliding simulation.

\begin{tabular}{lcc}
\hline Parameter & Values & Units \\
\hline Bubble diameter & $1.10 \times 10^{-3}$ & $\mathrm{~m}$ \\
Bubble velocity & $1.80 \times 10^{-1}$ & $\mathrm{~m} \cdot \mathrm{s}^{-1}$ \\
Bulk liquid velocity & $2.0 \times 10^{-1}$ & $\mathrm{~m} \cdot \mathrm{s}^{-1}$ \\
Re channel & 18316 & $(-)$ \\
Re bubble & 140 & $(-)$ \\
Heat Flux & 1740 & $\mathrm{~W} \cdot \mathrm{m}^{-2}$ \\
Bulk Inlet Temperature & 38.5 & ${ }^{\circ} \mathrm{C}$ \\
\hline
\end{tabular}

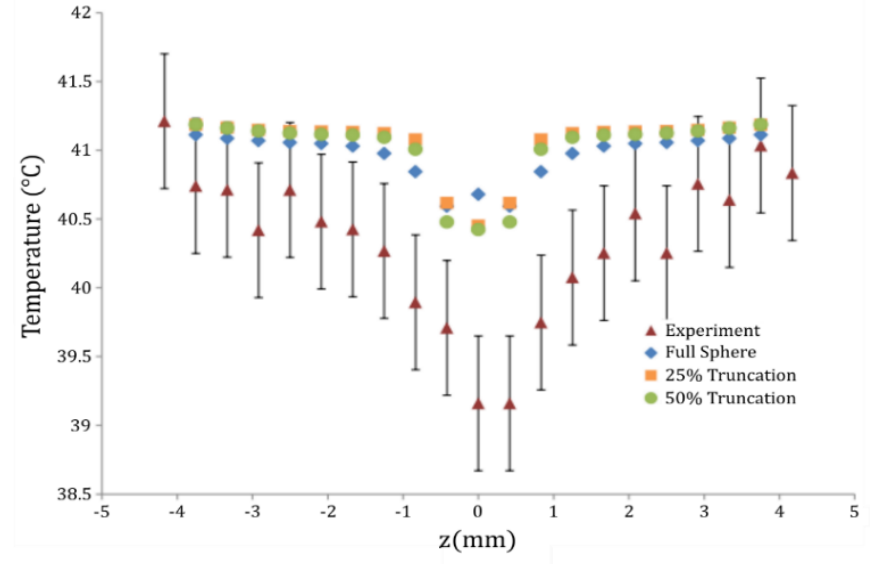

Fig. 9 Temperature distribution obtained from the experiment and the simulation for different bubble shapes.

Lateral Migration Influence In the previous section it is assumed that bubbles follow a straight trajectory. In reality, a small lateral displacement is observed. Therefore, a second bubble is placed in the flow field. This bubble is slightly shifted in the span-wise direction as shown in Fig. 10. The $0.16 \mathrm{~mm}$ offset chosen is estimated from the digital image processing code. Since the hemispherical bubble gave the largest heat transfer enhancement, this shape is re-used in this case. Figure 11 shows a similar peak temperature drop as observed for the inline case. The temperature distribution becomes asymmetrical, which could be expected because of the asymmetrical geometry. Once again, the large cooling effect observed on the experimental data is not observable here and cannot explain the large peak wall temperature drop.

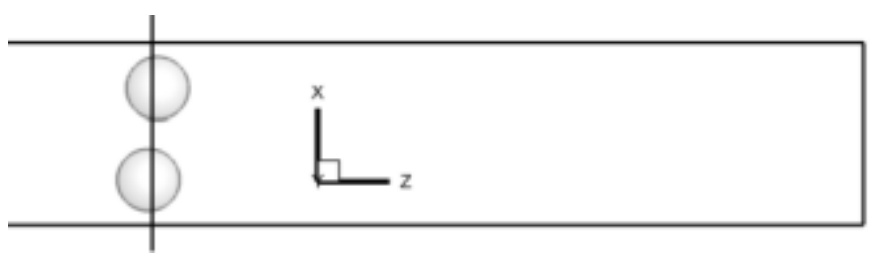

Fig. 10 Positioning of the bubbles in the computational domain.

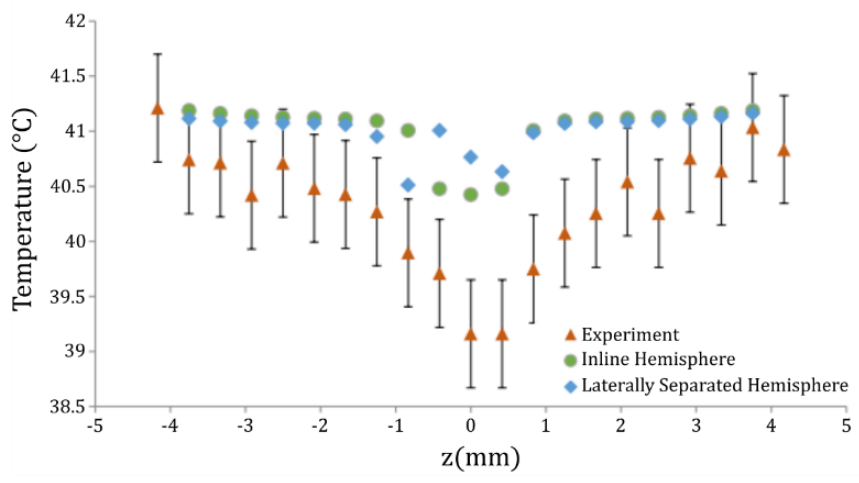

Fig. 11 Temperature distribution obtained from the experiment and the simulation for inline and separated bubble sliding.

\subsection{Stationary Bubble near Wall}

The heat transfer enhancement is also highly dependent on bubble relative velocity. Donnelly et al. (2009), (2012) conducted experiments of bubble sliding in natural convection, which corroborated that assumption. Similarly, the bubble causing the greatest disruption in a 
forced convection thermal boundary layer is the one with the highest Reynolds number (large relative velocity and bubble diameter); this corresponds to the bubble just departing the injection or nucleation site. Hence, the disruption in the thermal boundary layer caused by a stationary bubble would be the highest possible and thus could be the dominant mechanism in heat transfer enhancement. To the author's knowledge, this mechanism of heat transfer enhancement has never been identified in forced convective flow. Donnelly et al. (2015) identified a high Reynolds number heat transfer enhancement mechanism for sliding bubbles in a natural convection heat transfer mode. To simulate the forced convection case with the highest bubble Reynolds number, the assumption is made that the bubble absolute velocity is zero immediately after being released from the injection site.

Domain Geometry, Mesh \& Boundary Conditions The computational domain is modeled after the experimental setup. The dimensions of the bubbles are chosen using the digital image processing code. As in the sliding case, the flow is assumed to be symmetrical to reduce the computational costs and time. Therefore, as shown in Fig. 12, half of the channel is simulated. The origin of the domain is placed at the center of the sphere and its dimension are in millimeters as given below. The boundary conditions used in this case are summarized in Table 5.

$$
\left\{\begin{array}{c}
-10 * d<x<10 * d \\
-\left(\frac{d}{2}+\varepsilon\right)<y<10-\left(\frac{d}{2}+\varepsilon\right) \\
0<z<12.5
\end{array}\right.
$$

The mesh employed is a uniformly fine mesh that was first tested on the validation cases to ensure convergence and stability. The micro-layer region is meshed with $6.75 \mu \mathrm{m}$ cells with at least 16 cells in the thinnest region of the domain.

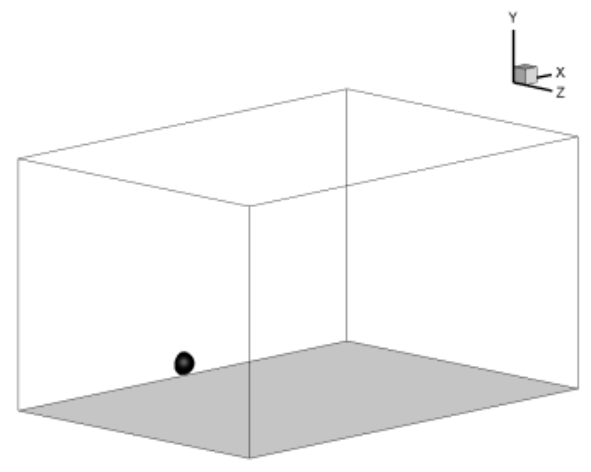

Fig. 12 Computational domain geometry for the stationary bubble case.

Table 5 Boundary conditions specified for the stationary bubble simulation.

\begin{tabular}{lll}
\hline Boundary Conditions & Hydrodynamic & Thermal \\
\hline Inlet & Velocity Inlet & Fixed Temperature \\
Outlet & Pressure Outlet & Temperature Outlet \\
Bubble & No Shear & Adiabatic \\
Bottom Wall & No Slip & Constant Heat Flux \\
Side Wall & No Slip & Adiabatic \\
Symmetry Plane & Symmetry Plane & Symmetry Plane \\
Top Wall & No Slip & Adiabatic \\
\hline
\end{tabular}

Cases Considered Two different flow setups are considered in this work corresponding to two different bulk flow Reynolds number. Those parameters are summarized in Table 6. To ensure the validity of the physics of the results, the velocities and temperature fields are compared with those from the corresponding channel flow. In other words, it is computationally ensured that the velocity and temperature profiles in the vertical direction remain unaffected far from the wall whether a bubble is present or not.

Table 6 Governing flow parameters for the stationary cases.

\begin{tabular}{lrrc}
\hline Parameter & Case 1 & Case 2 & Units \\
\hline Bubble diameter & $9.0 \times 10^{-4}$ & $1.1 \times 10^{-3}$ & $m$ \\
Micro-Layer Thickness & 50 & 50 & $\mu m$ \\
Re channel & 25643 & 18316 & $(-)$ \\
Re bubble & 1441 & 1338 & $(-)$ \\
Bulk Inlet Temperature & 38.21 & 38.5 & ${ }^{\circ} \mathrm{C}$ \\
Heat Flux & 1714 & 1740 & $W . m^{-2}$ \\
\hline
\end{tabular}

Figures 13 and 14 represent the temperature field and skin friction coefficient on the bottom wall for both cases. The skin friction coefficient shows its peak value close to the bubble vertical axis where the flow is highly pressurized because it has to get through the collar imposed by the thin micro-layer region. The consequence of the flow expansion is that the region following has the lowest skin friction coefficient value. The second case shows a higher skin friction coefficient both at the peak value and in the wake as it is inversely related to the bulk Reynolds number. The higher skin friction coefficient values observed in the wake suggest an enhancement in the heat transfer coefficient compared to the region outside the wake. This is confirmed by Fig. 13 where the temperature is lower in high skin friction coefficient areas.

Figure 13b shows a higher far field temperature than on Fig. 13a, which could be expected as this part of the wall is only exposed to single phase forced convection, which is proportional to the Reynolds number. The enlarged view in Fig. 13b shows a yellow streak in the green region, which is due to the warmer upward flow coming from the near wall region. This cannot be observed in the experiment because it is an average of thousands of bubbles.

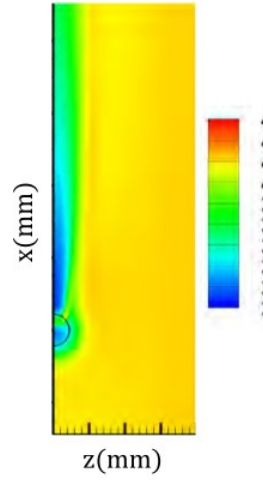

(a)

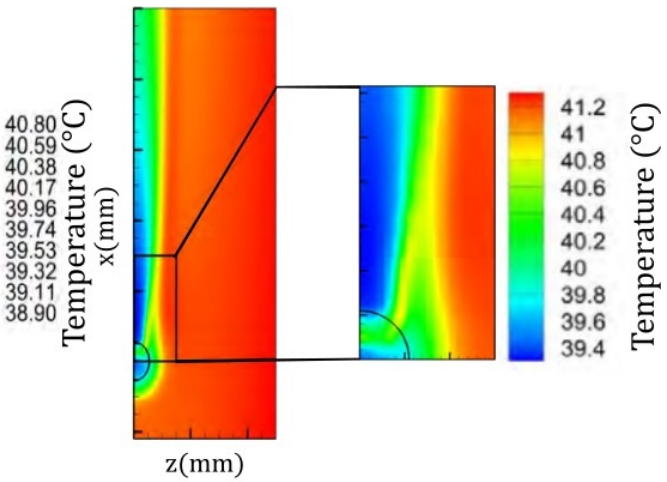

(b)
Fig. 13 Contour plot of the temperature field on the heated wall. (a) Case 1, (b) Case 2.

Figures 15 to 17 show the computed and measured temperature distribution in the span-wise direction for different stream-wise coordinates for Cases 1 and 2. On Fig. 15, the heater wall peak temperature drop globally agrees with the experimental measurements. The systematic temperature gap between the computed and measured temperature field is likely due to simplifications in the numerical model that does not take into account three transient phenomena: 1) bubble growth, 2) acceleration of the previous bubble, and 3) coalescence between bubbles. Because of a lower impact of those phenomena, the temperature deviation between experimental and numerical results closes away from the center line where $|z|>4 \mathrm{~mm}$.

Figures 16 and 17 show an improving agreement between computed and measured temperature distribution, which corroborates the conjecture that the enhanced heat transfer is due to the disturbance 
created by the bubble while still at the injection or nucleation site, where the bubble Reynolds number is greatest. Although the experimentally measured temperature profiles are the average of multiple bubbles disrupting the thermal boundary layer, the numerical profiles of a single stationary bubble agree well with the former. The lower measured temperatures observed on Fig. 15 to 17 at $z=-4 \mathrm{~mm}$ are due to small bubbles sliding at the edges of the heater caused by unwanted boiling. The good agreement observed for both cases corroborates the idea that the mechanism responsible for the heat transfer enhancement is mainly due to the stationary bubble at the injection or nucleation site rather than sliding bubbles in the wake. This enhancement can be explained through the computed flow field around the bubble. Figure 18 shows the streamlines along the plane $z=300 \mu \mathrm{m}$ with the temperature field in the background. The presence of the bubble diverts the cold fluid coming from the bulk flow downward and the fluid coming from the wall region is diverted upward downstream of the bubble. These phenomena lead to significant mixing between the cold and warmer fluid in the wake of the bubble and therefore, there is a corresponding decrease in the wall temperature. Figure 18 also shows the area of influence that the single bubble has on the flow downstream. Indeed, the streamlines are completely converged $6 \mathrm{~mm}$ downstream, which is more than six times the bubble diameter. It is also understandable that this mechanism of heat transfer enhancement would easily cover any contribution of the local bubble sliding in the wake for a considerable distance.

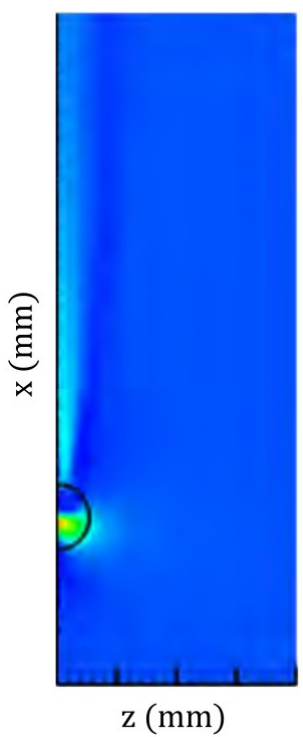

(a)

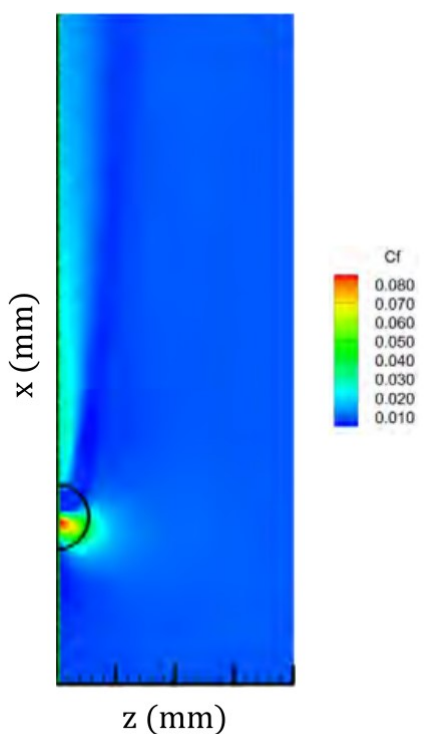

(b)

Fig. 14 Contour plot of skin friction coefficient on the heated wall. (a) Case 1, (b) Case 2.

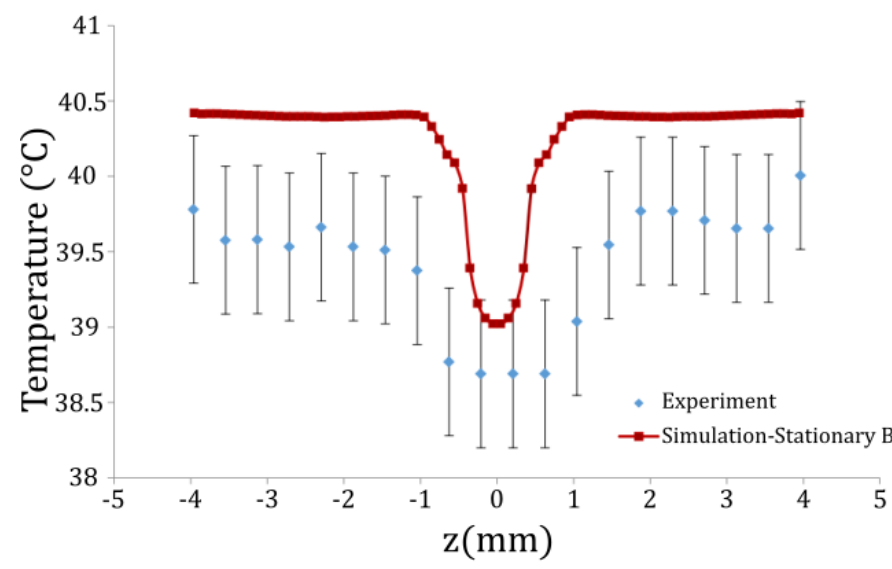

(a)
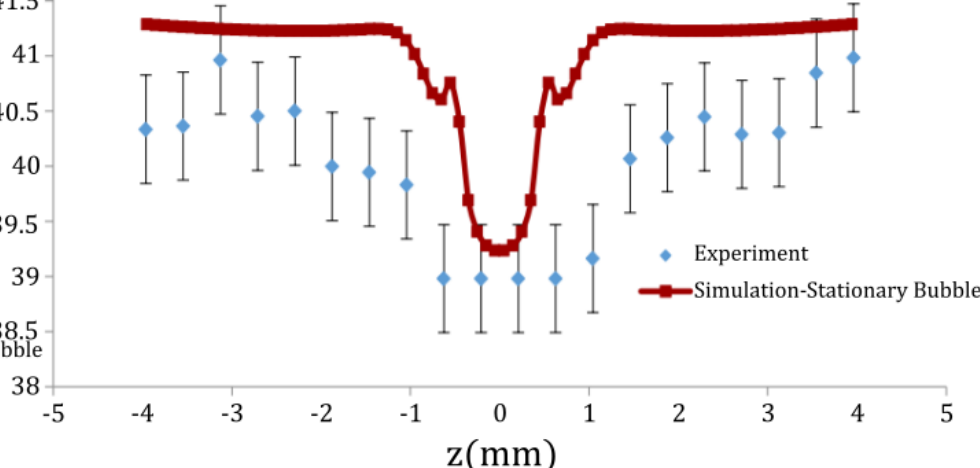

(b)

Fig. 15 Temperature distribution in the span-wise direction for numerical and experimental results at $x=1 \mathrm{~mm}$. (a) Case 1 , (b) Case 2 .

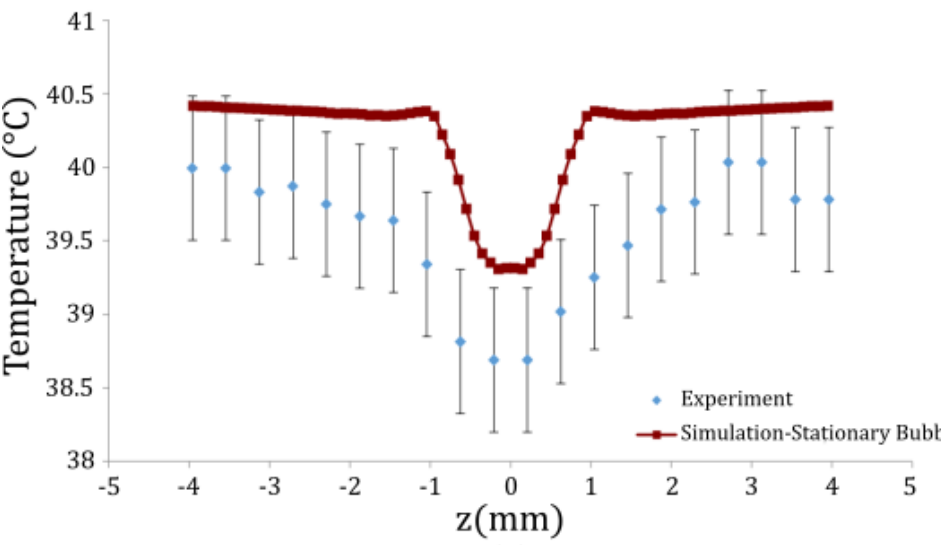

(a)

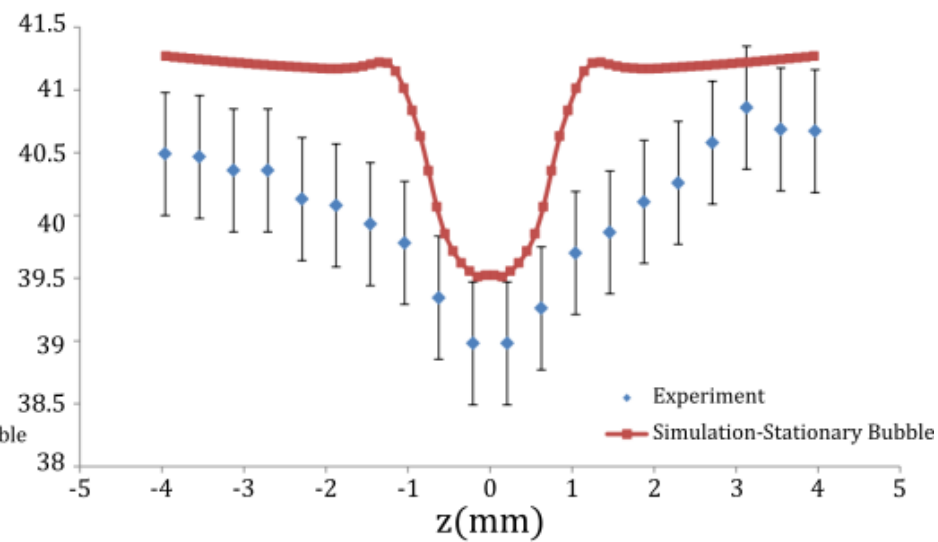

(b)

Fig. 16 Temperature distribution in the span-wise direction for numerical and experimental results at $x=40 \mathrm{~mm}$. (a) Case 1 , (b) Case 2 . 


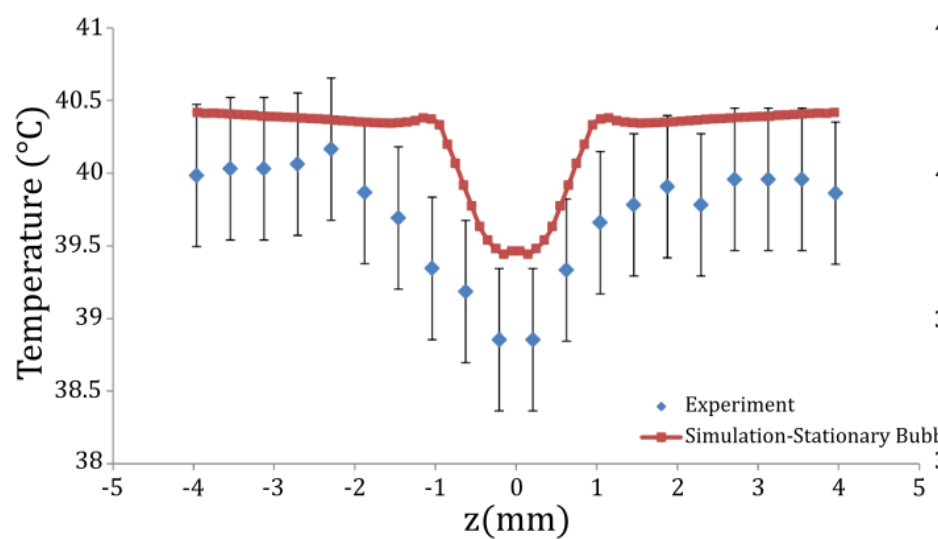

(a)

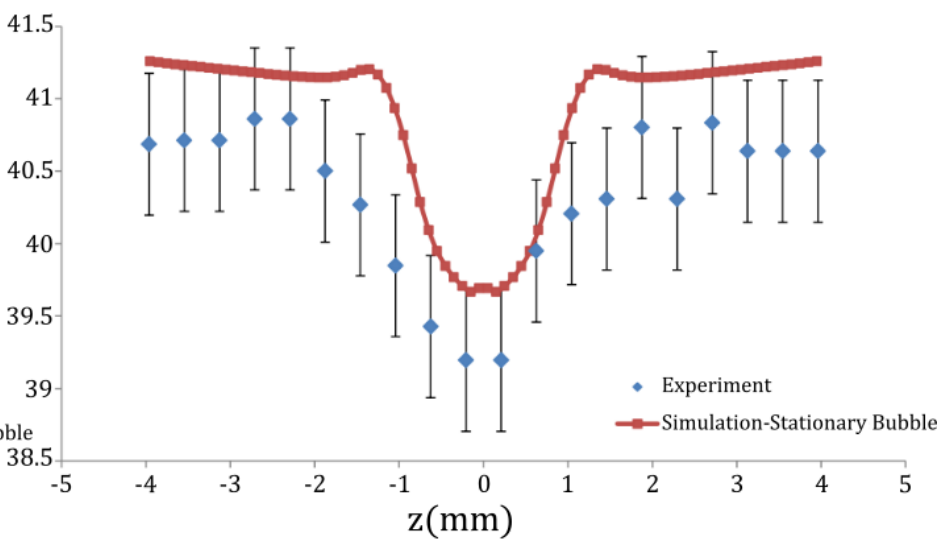

(b)

Fig. 17 Temperature distribution in the span-wise direction for numerical and experimental results at $x=56 \mathrm{~mm}$. (a) Case 1 , (b) Case 2 .

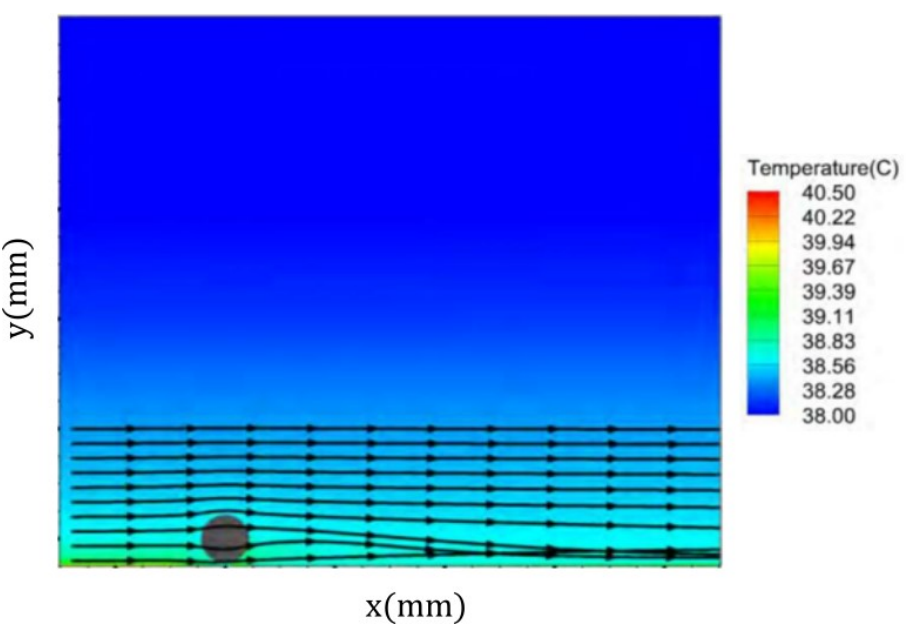

Fig. 18 Contour plot of streamlines and temperature field for $Z=$ $300 \mu \mathrm{m}$.

Micro-Layer Thickness Influence In the previous section, a $50 \mu \mathrm{m}$ micro-layer thickness is used and the computed results reasonably agree with the experiments. As suggested by Addlesee and Kew (2002), the typical range for micro-layer thickness is between $50 \mu \mathrm{m}$ and $100 \mu \mathrm{m}$. Hence, an increase of $50 \%$ from the original value is studied and compared. All other fluid parameters used are the same as case number one in Table 6.

The temperature contours in Fig. 19 do not show any appreciable difference for an increased micro-layer thickness. The yellow streak in the intermediate region is slightly larger when the bubble is closer to the wall. The temperature distributions are shown in Fig. 20, and with both curves overlapping on one another, the lack of sensitivity to microlayer thickness is confirmed. Thus, it can be concluded that the micro-layer thickness does not have a significant influence on heat transfer enhancement.

Bubble Shape Influence For the purpose of analyzing the heat transfer enhancement sensitivity to bubble shape, spherical and $25 \%$ truncated spheres are considered, and the temperature distribution is compared for different stream-wise positions. A truncated sphere with the same micro-layer thickness gives an increase in the base area and a diminution of the bubble height compared with the spherical bubble. Despite this modified geometry, the temperature profiles shown in Fig. 21 almost lie on each other for $x=1 \mathrm{~mm}$. As the flow proceeds downstream $(40 \mathrm{~mm})$, the wake is slightly larger for the truncated sphere, which is reasonable, considering the wider base area. On the other hand, the wall peak temperature drop remains unaffected by the shape modification.

Two Stationary Spherical Bubbles The presence of bubbles sliding in the wake of a stationary bubble, as is the case in the experiment, should be accounted for in heat transfer enhancement. However, modeling an accelerating bubble downstream of a stationary bubble is very complex. Therefore, it is assumed that bubble acceleration is almost nil right after detachment; so the bubble downstream of the stationary bubble can be considered stationary as well. The center line distance chosen here is $1.3 \mathrm{~mm}$. As shown in Fig. 22a, the presence of a second bubble considerably alters the temperature field in the vicinity of the bubbles by increasing both the magnitude and the width of the wall peak temperature drop. This could be expected as the fluid path is diverted by two bubbles instead of one. This bubble configuration also improves the comparison between measured and computed temperature profiles. As shown in Fig. $22 \mathrm{~b}$, the downstream difference between the two cases diminishes as the influence of the second bubble on the flow is lesser.

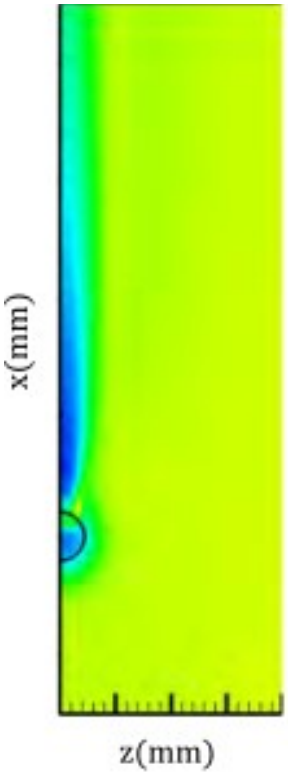

(a)

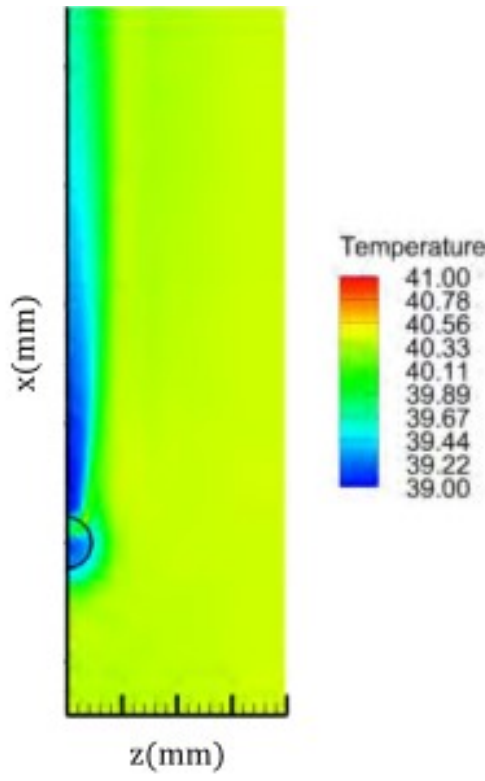

(b)
Fig. 19 Contour plot of the temperature on the heated wall. (a) $50 \mu \mathrm{m}$ (b) $75 \mu \mathrm{m}$. 

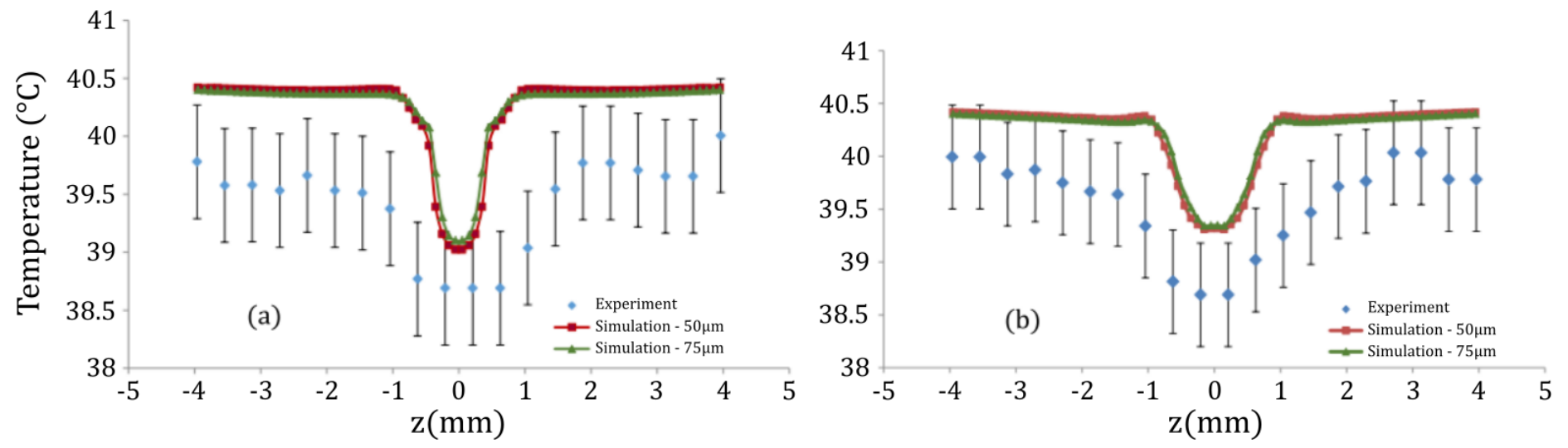

Fig. 20 Temperature distribution in the span-wise direction for $50 \mu \mathrm{m}, 75 \mu \mathrm{m}$ micro-layer thickness and experimental results. (a) $x=1 \mathrm{~mm}$, (b) $x=$ $40 \mathrm{~mm}$.

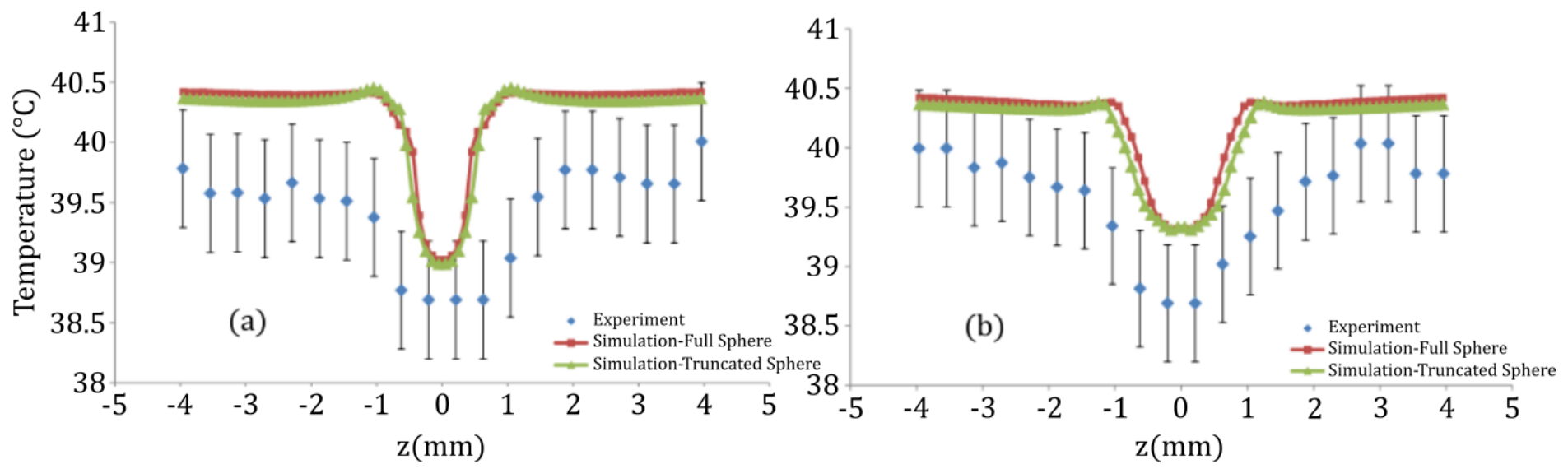

Fig. 21 Temperature distribution in the span-wise direction for a full sphere, $25 \%$ truncated sphere and experimental results. (a) $x=1 \mathrm{~mm}$, (b) $x=$ $40 \mathrm{~mm}$.
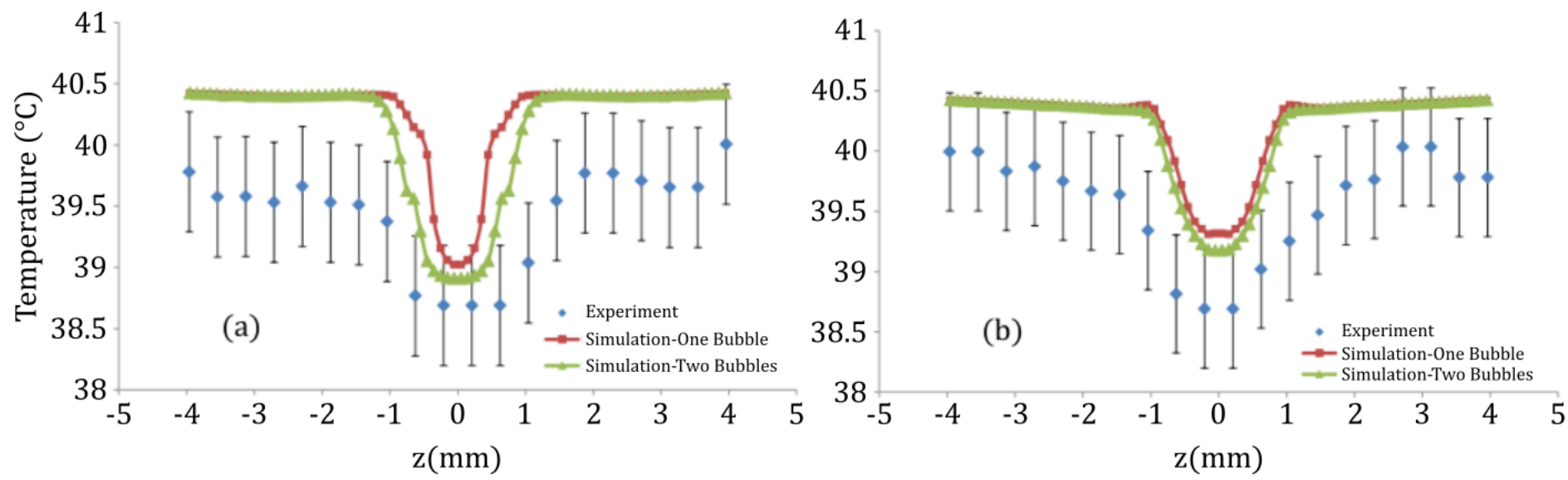

Fig. 22 Temperature distribution in the span-wise direction for a single stationary bubble, two inline stationary bubbles and experimental results. (a) $x=1 \mathrm{~mm}$, (b) $x=40 \mathrm{~mm}$

\section{CONCLUSION}

A new forced convection heat transfer experimental facility that allows visual access on the three sides of the heated section was fabricated. Thermochromic Liquid Crystals and two high-speed cameras are used to simultaneously measure the heating surface temperature field and the bubble dynamics. Simultaneously, a numerical analysis which includes a parametric evaluation on sliding and stationary bubbles was conducted revealing several important issues associated with sliding bubble heat transfer enhancement. The computed temperature field on the heated wall for a sliding bubble does not agree well with the experimental results. The enhanced cooling observed for the experiments is significantly larger than that computed for a sliding bubble. Thus, it is inferred that the bubble sliding mechanism has a much lower impact on the heat transfer enhancement than is widely suggested in the literature. This confirms the observation made by Donnelly et al. (2015) that the 
bubble Reynolds number is the main parameter driving the heat transfer enhancement both in natural convection and in forced convective flow.

The temperature distribution computed for the stationary bubble analysis is in approximate agreement with the experimental measurements. The positioning of a bubble at the injection or nucleation site presents a significant obstacle that diverts the mean flow and promotes strong mixing in both the vicinity and further downstream from the bubble site. The cold bulk fluid flows downward and the warmer fluid flows upward leading to turbulent mixing that disrupts the thermal boundary layer downstream. It is concluded that the heat transfer enhancement mechanism in forced convection turbulent flows is mainly due to the flow disturbance initiated by the stationary bubble at the injection or nucleation site rather than sliding bubbles in the wake.

For both stationary and sliding bubble cases, the influence of the micro-layer thickness and bubble shape does not significantly affect the thermal field. Finally, the presence of a second stationary bubble in the wake widens the peak wall temperature drop in the vicinity of the bubbles. The presence of multiple bubbles downstream will enhance the impact of the stationary one with a decreasing influence as the bubbles are transported downstream.

There exist many mechanistic flow boiling correlations, such as those of Chen (1966), Gungor and Winterton (1986), Kandlikar (1990), Mueller-Steinhagen and Heck (1986), Thome et al. (2004), among others where bulk turbulent enhancement ignores the sliding bubble heat transfer enhancement mechanism. There has been debate as to whether sliding bubbles should be accounted for in predicting bulk turbulent enhanced heat transfer in flow boiling. The results from this investigation provide significant insight as to why flow boiling correlations are successful without considering the dynamics of sliding bubbles.

\section{NOMENCLATURE}

$d \quad$ Bubble diameter (m)

$U \quad$ Free stream velocity $(\mathrm{m} / \mathrm{s})$

$C_{f} \quad$ Friction coefficient (-)

Greek Symbols

$\begin{array}{ll}\varepsilon & \text { Micro-layer thickness }(\mu \mathrm{m}) \\ \rho & \text { density }\left(\mathrm{kg} / \mathrm{m}^{3}\right) \\ \tau_{w} & \text { Shear stress }(\mathrm{Pa})\end{array}$

\section{REFERENCES}

Addlesee, A. J., and Cornwell, K. (1997). "Liquid Film Thickness Above a Bubble Rising Under an Inclined Plate." Transcations Inst. Chem. Eng. 75, 663-667.

http:/dx.doi.org/10.1205/026387697524290

Addlesee, A. J., and Kew, P. A. (2002). "Development of the Liquid Film Above a Sliding Bubble." Chem. Eng. Res. Des. 80, 272-277.

http://dx.doi.org/10.1205/026387602753582042

Basu, N., Warrier, G. R., and Dhir, V. K. (2005). "Wall Heat Flux Partitioning During Subcooled Flow Boiling: Part 1-Model Development." J. Heat Transfer 127, 131.

http://dx.doi.org/10.1115/1.1842784

Chen, J. C. (1966). "Correlation for Boiling Heat Transfer to Saturated Fluids in Convective Flow." Ind. Eng. Chem. Process Des. Dev. 5, 322-329.

http://dx.doi.org/10.1021/i260019a023

Dean, R. B. (1978). "Reynolds Number Dependence of Skin
Friction and Other Bulk Flow Variables in Two-Dimensional Rectangular Duct Flow." J. Fluids Eng. 100, 215-223. http://dx.doi.org/10.1115/1.3448633

Donnelly, B., O'Donovan, T. S., and Murray, D. B. (2009). "Surface Heat Transfer Due to Sliding Bubble Motion." Appl. Therm. Eng. 29, 1319-1326. http://dx.doi.org/10.1016/j.applthermaleng.2008.09.002

Donnelly, B., O’Reilly Meehan, R., Nolan, K., and Murray, D. B. (2015). "The Dynamics of Sliding Air Bubbles and the Effects on Surface Heat Transfer." Int. J. Heat Mass Transf. 91, 532-542. http://dx.doi.org/10.1016/j.ijheatmasstransfer.2015.07.133

Donnelly, B., Robinson, A. J., Delauré, Y. M. C., and Murray, D. B. (2012). "Sliding Bubble Dynamics and the Effects on Surface Heat Transfer." J. Phys. Conf. Ser. 395.

http://dx.doi.org/10.1088/1742-6596/395/1/012180

Durbin, P. A. (1991). "Near-wall turbulence closure modeling without damping functions." Theor. Comput. Fluid Dyn. 3, 1-13. http://dx.doi.org/10.1007/BF00271513

Gungor, K. E., and Winterton, R. H. S. (1986). "A General Correlation for Flow Boiling in Tubes and Annuli." Int. J. Heat Mass Transf. 29, 351-358.

http://dx.doi.org/10.1016/0017-9310(86)90205-X

Ireland, P. T., and Jones, T. V. (1987). "The Response Time of a Surface Thermometer Employing Encapsulated Thermochromic Liquid Crystals. J. Phys. E. 20, 1195-1199.

http://dx.doi.org/10.1088/0022-3735/20/10/008

Kandlikar, S. G. (1990). "A General Correlation for Saturated Two-Phase Flow Boiling Heat Transfer Inside Horizontal and Vertical Tubes." J. Heat Transfer 112, 219.

http://dx.doi.org/10.1115/1.2910348

Kenning, D. B. R., and Kao, Y. S. (1972). "Convective Heat Transfer to Water Containing Bubbles: Enhancement not Dependent on Thermocapillarity." Int. J. Heat Mass Transf. 15, 1709-1717.

http://dx.doi.org/10.1016/0017-9310(72)90099-3

Kim, J., and Lee, J. S. (2017). "Surface-Wettability-Induced Sliding Bubble Dynamics and its Effects on Convective Heat Transfer." Appl. Therm. Eng. 113, 639-652. http://dx.doi.org/10.1016/j.applthermaleng.2016.11.097

Kitagawa, A., Kosuge, K., Uchida, K., and Hagiwara, Y. (2008). "Heat Transfer Enhancement for Laminar Natural Convection Along a Vertical Plate Due to Sub-Millimeter-Bubble Injection." Exp. Fluids 45, 473-484. http://dx.doi.org/10.1007/s00348-008-0490-8

Kline, S. J., and McClintock, F. A. (1953). "Describing Uncertainties in Single-Sample Experiments." Mech. Eng. 75, 38.

Li, X., Hollingsworth, D. K., and Witte, L. C. (2006). "The Thickness of the Liquid Microlayer between a Cap-Shaped Sliding Bubble and a Heated Wall: Experimental Measurements." J. Heat Transfer 128, 934-944. http://dx.doi.org/10.1115/1.2241858

Lindken, R., and Merzkirch, W. (2001). "A Novel PIV Technique 
for Measurements in Multi-Phase Flows and its Application to Two-Phase Bubbly Flows." DLR-Mitteilung 33, 991-1003. http://dx.doi.org/10.1007/s00348-002-0500-1

Mei, R., Klausner, J. F., and Lawrence, C. J. (1994)."A Note on the History Force on a Spherical Bubble at Finite Reynolds number." Phys. Fluids 6, 418-420.

http://dx.doi.org/10.1063/1.868039

Muller-Steinhagen, H., and Heck, K. (1986). "A Simple Friction Pressure Drop Correlation for Two-Phase Flow in Pipes." Chemical Engineering and Processing: Process Intensification., 20, 297-308. http://dx.doi.org/10.1016/0255-2701(86)80008-3

Muwanga, R., and Hassan, I. (2006). "Local Heat Transfer Measurements in Microchannels Using Liquid Crystal Thermography: Methodology Development and Validation." $J$. Heat Transfer 128, 617. http://dx.doi.org/10.1115/1.2193541

O’Reilly Meehan, R., Donnelly, B., Nolan, K., and Murray, D. B. (2017). Bubble-wake interactions of a sliding bubble pair and the mechanisms of heat transfer. Int. J. Heat Mass Transf. 108, 13471356.

http://dx.doi.org/10.1016/j.ijheatmasstransfer.2017.01.017

Ozer, A. B., Oncel, A. F., Hollingsworth, D. K., and Witte, L. C. (2011). "A Method of Concurrent Thermographic-Photographic Visualization of Flow Boiling in a Minichannel." Exp. Therm. Fluid Sci. 35, 1522-1529.

http://dx.doi.org/10.1016/j.expthermflusci.2011.07.002

Sabatino, D. R., Praisner, T. J., and Smith, C. R. (2000). "A HighAccuracy Calibration Technique for Thermochromic Liquid Crystal Temperature Measurements." Exp. Fluids 28, 497-505. http://dx.doi.org/10.1007/s003480050411

Son, G. (2001). "Numerical Study on a Sliding Bubble During Nucleate Boiling." KSME Int. J. 15, 931-940.

http://dx.doi.org/10.1007/BF03185271
Sparrow, E. M., Lloyd, J. R., and Hixon, C. W. (1966). Experiments of Turbulent Heat Transfer in an Asymmetrically Heated Rectangular Duct." Trans. ASME, 170-174. http://dx.doi.org/10.1115/1.3691505

Thome, J. R., Dupont, V., and Jacobi, A. M. (2004). "Heat Transfer Model for Evaporation in Microchannels." Part I: Presentation of the Model." Int. J. Heat Mass Transf. 47, 33753385.

http://dx.doi.org/10.1016/j.ijheatmasstransfer.2004.01.006

Thorncroft, G. E., Klausner, J. F., and Mei, R. (1998). "An Experimental Investigation of Bubble Growth and Detachment in Vertical Upflow and Downflow Boiling." Int. J. Heat Mass Transf. 41, 3857-3871. http://dx.doi.org/10.1016/S0017-9310(98)00092-1

Thorncroft, G. E., Klausner, J. F., and Mei, R. (2001). Bubble forces and detachment models. Multiph. Sci. Technol. 13, 35-76. http://dx.doi.org/10.1615/MultScienTechn.v13.i3-4.20

Wagner, E., and Stephan, P. (2007). Frequency Response of a Surface Thermometer Based on Unencapsulated Thermochromic Liquid Crystals." Exp. Therm. Fluid Sci. 31, 687-699. http://dx.doi.org/10.1016/j.expthermflusci.2006.07.003

Weiss, B. Y. P. (1944). "On Hydrodynamical Images. Arbitrary Irrotational Flow Disturbed by a Sphere." Math. Proc. Cambridge Philos. Soc. 40, 259-261. http://dx.doi.org/10.1017/S0305004100018430

Yeoh, G. H., Cheung, S. C. P., Tu, J. Y., and Ho, M. K. M. (2008). "Fundamental Consideration of Wall Heat Partition of Vertical Subcooled Boiling Flows." Int. J. Heat Mass Transf. 51, 3840 3853.

http://dx.doi.org/10.1016/j.ijheatmasstransfer.2007.11.047 